\title{
MEGALITIK DAN CERITA RAKYAT SUKU BAHAM DI GUA SOSOSRAWERU FAK-FAK \\ (Megalithic and Folklore of Baham Tribe in the Sosoraweru Cave Fak-Fak)
}

\author{
Rini Maryone \\ Balai Arkeologi Jayapura \\ maryonerini@gmail.com
}

\begin{abstract}
Megalith Papua is the actual activity with medium natural stones such as stalagmites and stalagtik in a cave, a dolmen, stone sculptures and other natural stones are considered to be the reincarnation of the spirits of ancestors, as found in the cave Sosoreweru. In this study conducted in the Cave Sosoraweru Forir village in the district of Coke, Fakfak. The methods used in this study is the method of data collection includes library research, field surveys, using the approach Ethnoarchaeology. The results of the study in the form of 4 pieces shaped stone menhirs. based on these findings may reveal molar tribal folklore in the village district Forir the consortium. Folklore have utility in a common life, as a means of educators, entertainment, social protest and the projection of a pent-up desire.
\end{abstract}

Keywords: megalithic remains, stone sculptures, folklore

\begin{abstract}
ABSTRAK
Megalitik Papua merupakan kegiatan aktual dengan media batu-batu alam seperti stalagmit dan stalagtik dalam gua, dolmen, batu pahatan dan batu-batu alam lainnya yang dianggap sebagai jelmaan roh-roh nenek moyang. Penelitian ini dilakukan di Gua Sosoraweru, Kampung Forir di Distrik Kokas, Kabupaten Fakfak. Adapun metode yang digunakan dalam penelitian ini adalah metode pengumpulan data yang meliputi studi pustaka, survei lapangan, dan analisis menggunakan pendekatan etnoarkeologi. Hasil penelitian berupa empat buah batu berbentuk menhir. Berdasarkan temuan tersebut dapat mengungkapkan cerita rakyat suku Baham di Kampung Forir, Distrik Fakfak. Cerita rakyat mempunyai fungsi sebagai media pendidikan, hiburan, protes sosial dan proyeksi suatu keinginan yang terpendam.
\end{abstract}

Kata kunci: tinggalan megalitik, menhir, cerita rakyat

Tanggal masuk : 5 September 2014

Tanggal diterima : 3 November 2014 


\section{PENDAHULUAN}

Pengertian megalitik telah banyak disinggung oleh para ahli yaitu sebagai suatu tradisi yang menghasikan batu-batu besar, mengacu pada etimologinya yaitu besar dan lithos berarti batu (Soejono 1984 : 205). Dengan demikian dapat dikemukakan bahwa kebudayaan megalitik pada umumnya mempunyai cakupan yang luas, terutama yang menyangkut peninggalan-peninggalan batu-batu besar. Disamping itu kebudayaan megalitik oleh beberapa ahli cenderung dikaitkan dengan pemujaan terhadap nenek moyang.

Istilah "megalitik" bukan merupakan masa megalitik atau budaya megalitik tetapi merupakan tradisi yang berkembang dari masa neolitik sampai masa perunggu besi bahkan berlanjut sampai sekarang (Geldern, 1945; Van Heekeren, 1958; Soejono, 1981). Sebagai gambaran umum dapat dikemukakan biasanya uraian tentang tradisi megalitik bersifat universal, karena hampir terdapat di semua benua, kecuali Australia yang tidak mengandung tandatanda adanya kebudayaan megalitik (Callenfeless, 1961 : 34; Belwood, 1975 : 281-380; Soejono, 1984 ; 242). Dalam tradisi ini terkandung dalam alam pikiran yang bersifat religius dan kepercayaan tersebut juga dimiliki bangsa-bangsa lainnya seperti

Asia Tenggara dan Pasifik. Tradisi megalitik ini berlangsung sejak masa prasejarah hingga sekarang (Hoop, 1932 : 101 dalam Prasetyo, 2004 : 95). Sejauh ini peninggalanpeninggalan megalitik belum banyak diselidiki. Para peneliti antropologi budaya karena pada umumnya masih kurang sekali mengaitkan masalah bangunan megalitik dengan kehidupan masyarakat sederhana. Sedangkan tradisi megalitik (living megalithic) di Indonesia dapat ditemukan di beberapa wilayah antara lain terdapat di Nias,
Toraja, Sumba, dan Flores (Geldern, 1945: 129; Soejono, 1984 : 306312), dan termasuk di wilayah Papua, untuk luar Indonesia tradisi megalitik berlanjut ini terdapat di daerah Assam, Birma, Serawak (Heekeren, 1958 : 44), Kepulauan Luzon (Philipina) serta Siam utara (Wales, 1958).

Papua menerima pengaruh megalitik dari Asia Tenggara lewat rute barat melalui kepulauan Indonesia bagian selatan, Maluku, selanjutnya memasuki Kepala Burung; dan pengaruh megalitik juga menyebar melalui Mikronesia, sebelum menuju ke barat menuju Sepik di Papua Nugini melalui Filipina, Sulawesi Utara, dan Halmahera (Soejono, 1994 :30). Megalitik di Papua berbeda dengan bentuk megalitik yang ditemukan di wilayah Indonesia bagian barat dan sebagian Indonesia bagian timur (Sulawesi tengah, dan utara). Megalitik di Papua lebih dicirikan oleh pola yang sederhana yang mirip dengan bentuk-bentuk yang ada di Indonesia bagian timur seperti, Maluku dan Nusa Tenggara Timur (Prasetyo, 2011 : 88). Persebaran unsur-unsur megalitik juga ditemukan di Papua. Riesenfeld pada tahun 1950 pernah melaporkan kehadiran kubur-kubur batu, temboktembok batu serta tempat persajian yang tersebar pada Pulau Adi, Namatota, Patipi, Fu-um, Ora, Batanta, Sorong dan Numfor, Sungai Karufa, Skroe, Sisir dan Bintuni, serta sekitar Danau Sentani (Riesenfeld, 1952 : 405-447; Galis, 1957 : 342).

Tradisi megalitik di Papua merupakan kegiatan ritual dengan menggunakan media batu-batu alam seperti stalagmit dan stalagtit dalam gua-gua, dolmen, batu pahatan dan batu-batu alam lainnya yang dianggap sebagai jelmaan roh-roh nenek moyang. Yang dilakukan baik secara perorangan dan kelompok. Kegiatan ritual ini menunjukkan adanya tradisi berlanjut dan sekaligus 
dapat menggambarkan sistem religi masa lampau orang Papua yang masih bertahan ditengah kehidupan masyarakat pemeluk agama Kristen dan Islam. Kegiatan ritual tersebut merupakan beberapa tindakan, seperti: berdoa, bersujud, bersaji, berkorban, makan bersama, menari dan menyanyi, berprosesi, berseni, drama suci, berpuasa, bertapa dan bersemedi. Bentuk kegiatan ritus tersebut nampak pada tradisi kepercayaan megalitik pada beberapa suku-suku yang ada di Papua, baik yang ada di pesisir maupun di pegunungan Papua termasuk masyarakat Kampung Forir, Fak-fak.

Peninggalan megalitik di Gua Sosoraweru terkait dengan cerita rakyat suku Baham, sebelum kita menelusuri cerita rakyat tersebut, terlebih dahulu kita memahami apa pengertian dari cerita rakyat. Cerita rakyat adalah prosa sastra lisan yang dilahirkan oleh masyarakat dan persebarannya atau pewarisannya dilakukan dengan cara lisan. Dalam cerita rakyat banyak ditemukan halhal yang kadang-kadang tidak dapat dipahami oleh logika manusia. Menurut Wliliam R. Bascom cerita rakyat dapat diklasifikasikan ke dalam tiga golongan, yaitu mite (myth), legenda (legend) dan dongeng (folktale) (Danandjaya dalam Lestari, 2012 : 21).

Cerita rakyat adalah cerita pada masa lampau yang menjadi ciri khas setiap bangsa yang memiliki kultur budaya yang beraneka ragam mencakup kekayaan budaya dan sejarah yang dimiliki masing-masing bangsa (abhasshare.blogspot.com). Cerita rakyat mempunyai kegunaan dalam kehidupan bersama, sebagai alat pendidik, hiburan, protes sosial dan proyeksi suatu keinginan yang terpendam. Sedangkan cerita rakyat bersifat pralogis yaitu logika yang khusus dan kadang berbeda dengan logika umum. Penelitian tentang cerita rakyat telah banyak dilakukan untuk berbagai macam tujuan (Danandjaja dalam Lestari, $2012: 21)$. Cerita rakyat dapat digali dari berbagai sumber, salah satu sumber yang penulis pakai di sini adalah berasal dari tinggalan megalitik yaitu batu-batu alam (stalagmit) yang disebut menhir. Dalam penulisan ini akan diangkat cerita rakyat, dari tinggalan megalitik yang terdapat di Gua Sosoraweru Kampung Forir Distrik Kokas Kabupaten Fakfak.

Untuk memudahkan alur berpikir, kerangka pikir yang penulis gunakan adalah tinjauan pustaka yang relevan dengan penulisan yaitu dimana penelitian tentang mengungkapkan cerita rakyat berdasarkan temuan benda purbakala di Pulau Ormu Kabupaten Jayapura oleh Umu Fatimah Ria Lestari. Dalam penelitiannya ada beberapa temuan benda purbakala di Pulau Ormu, dari temuan purbakala tersebut diduga memiliki asal-usul yang diceritakan dalam cerita rakyat suku Ormu. Konsep pemikiran inilah yang menjadi latar belakang penulisan ini dengan mengkaji tinggalan megalitik di Gua Sosoraweru Kampung Forir, Distrik Kokas, Kabupaten Fakfak.

Menurut Danandjaja, cerita rakyat secara umum didefinisikan sebagai bagian kebudayaan suatu kolektif yang tersebar dan diwariskan secara turun temurun (Lestari, 2012 : 21). Cerita rakyat adalah bagian dari sastra lisan, merupakan warisan budaya yang tidak ternilai harganya. Bangsa Indonesia adalah bangsa yang kaya akan nilainilai budaya, sehingga bangsa ini sangat menjunjung nilai-nilai budaya dalam kehidupan mereka sehari-hari. Nilai-nilai budaya itu kebanyakan masih tersimpan dalam berbagai bentuk, misalnya dalam adat istiadat dan tradisi. Ada pulah yang tersimpan dalam masyarakat berupa cerita rakyat atau dongeng-dongeng yang dilestarikan secara turun temurun. Keberadaan mitos dan dongeng 
ataupun cerita-cerita lain yang ada di Nusantara banyak sekali ragamnya. Ada yang memiliki kemiripan cerita atau bentuk varian cerita. Di dalam cerita ada khasanah yang tersirat antaranya pesan moral yang tersirat di dalam cerita itu (Edrasswara, 2013: 49).

Penelitian ini dilakukan di Kampung Forir, Distrik Kokas, Kabupaten Fakfak, Provinsi Papua Barat. Metode yang dilakukan yaitu pendekatan etnoarkeologi dengan memanfaatkan data etnografi sebagai analogi untuk memperoleh model kebudayaan masyarakat yang diteliti pada akhirnya dapat di proyeksikan pada kebudayaan masa lampau yang telah punah sehingga dapat membantu memecahkan masalah-masalah arkeologi.

Penelitian ini, dilakukan dengan dua tahap yaitu pengumpulan data dan pengolahan data. Pengumpulan data dilakukan dengan beberapa cara yaitu survei dengan pengamatan langsung terhadap objek yang diteliti. Wawancara dengan beberapa tokoh-tokoh guna mendapatkan informasi tentang objek yang diteliti. Melakukan studi pustaka dengan menelaah beberapa pustaka yang berkaitan dengan objek penelitian setelah semua data yang dibutuhkan terkumpul. Tahap akhir adalah pengolahan data, setelah semua data terkempul kemudian dideskrripsikan, dianalisis dan diinterpretasikan.

\section{PEMBAHASAN}

Wilayah Fakfak dengan luas $14.320 \mathrm{~km}^{2}$ secara geografis terletak di $131^{\circ} 30^{\prime}$ - $138^{\circ} 40^{\prime}$ BT dan antara $2^{\circ} 25^{\prime}-4^{\circ} 00^{\prime}$ LS. Daerah ini berbatasan langsung dengan Teluk Bintuni di sebelah utara, Laut Arafura dan Kabupaten Kaimana di sebelah selatan, Laut Seram dan Teluk Berau di sebelah barat, serta Kabupaten Kaimana di sebelah timur. Kabupaten Fakfak terdiri dari sembilan distrik yaitu, Distrik Teluk Patipi, Fakfak Barat, Fakfak Kota, Kokas, Kramongmongga, Fakfak Tengah, Bomberai, Fakfak Timur dan Karas (Tim Penelitian, 2012).

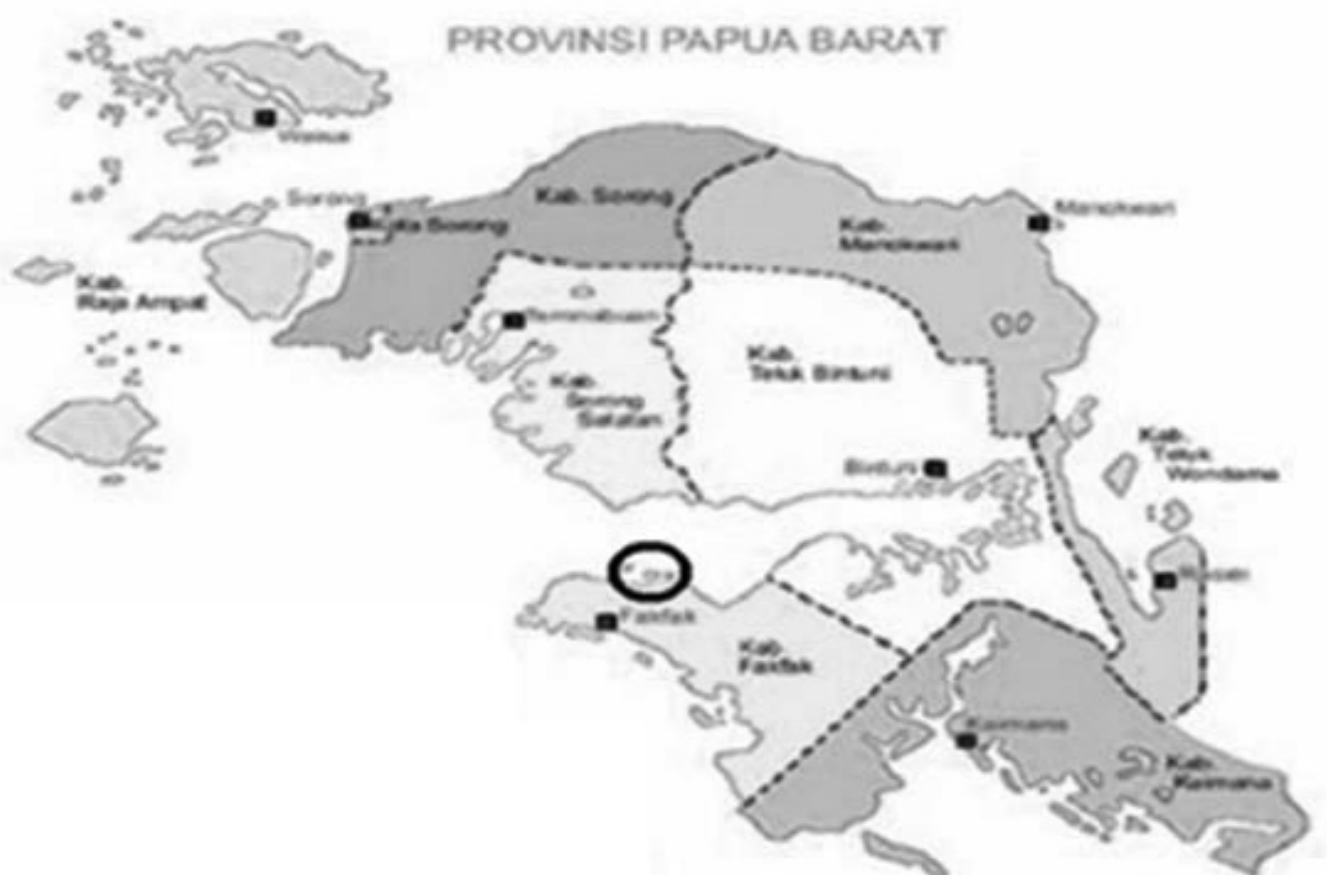

Peta 1. Provinsi Papua Barat dan Lokasi Penelitian 
Gua Sosoraweru secara administratif terletak di Kampung Forir, Distrik Kokas, Kabupaten Fakfak. Letak gua berada di sebelah timur Kampung Forir dengan koordinat $02^{\circ}$ 43.448' LS dan $132^{\circ} 37.796^{\prime}$ BT. Gua ini menghadap ke arah utara dan berada pada sisi lereng tebing, 4 meter di depan mulut gua terdapat air laut. Sosoraweru merupakan gua yang cukup besar. Mulut gua berada pada ketinggian kurang lebih 7 meter di atas permukaan laut dengan lebar mulut gua 5 meter dan tinggi mulut gua 3 meter, kedalaman/panjang gua 22 meter dan lebar17 meter. Lantai gua berupa tanah berwarna hitam kecoklatan yang rata di bagian muka dan miring ke bawah di bagian belakang, sehingga permukaan lantai gua di bagian muka lebih tinggi daripada di bagian belakang. Lantai gua kering di bagian depan dan lembab pada bagian belakang. Dinding gua berupa batu karang, di gua ini terdapat beberapa stalaktit dan stalagmit. Kondisi gua Sosoraweru cukup terang namun penetrasi sinar matahari tidak dapat menjangkau seluruh ruangan gua.

\section{Tinggalan Megalitik dan Cerita Rakyat}

Tinggalan arkeologis di Gua Sosoraweru, Kampung Forir, Distrik Kokas, Kabupaten Fakfak, berbentuk menhir dari bahan batu gamping (limestone). Menhir ini berjumlah 4 buah; 3 buah berukuran $150 \times 75 \times 40$ x $20 \mathrm{~mm}, 1$ buah lainnya berukuran $50 \times 40 \times 20 \mathrm{~mm}$. Peninggalan tradisi megalitik di daerah ini dihubungkan dengan tokoh yang digambarkan sebagai pendiri atau sesepuh yang berhubungan dengan legenda. Tinggalan megalitik ini terletak di dalam Gua Sosoraweru di Desa Forir.

Legenda tentang Gua Sosoraweru adalah tempat persembunyian sekaligus tempat tinggal anak manusia raksasa yang bernama kapitan. Sewaktu Suku Baham (suku-suku yang berada di daerah perbatasan FakfakSorong, Fakfak-Manokwari), kapitan berhasil melarikan diri menuju ke daerah pantai bersama-sama dengan rekan-rekan lainnya. Dalam pelarian tersebut dia belum mengetahui bahwa bapaknya tewas terbunuh. Pada

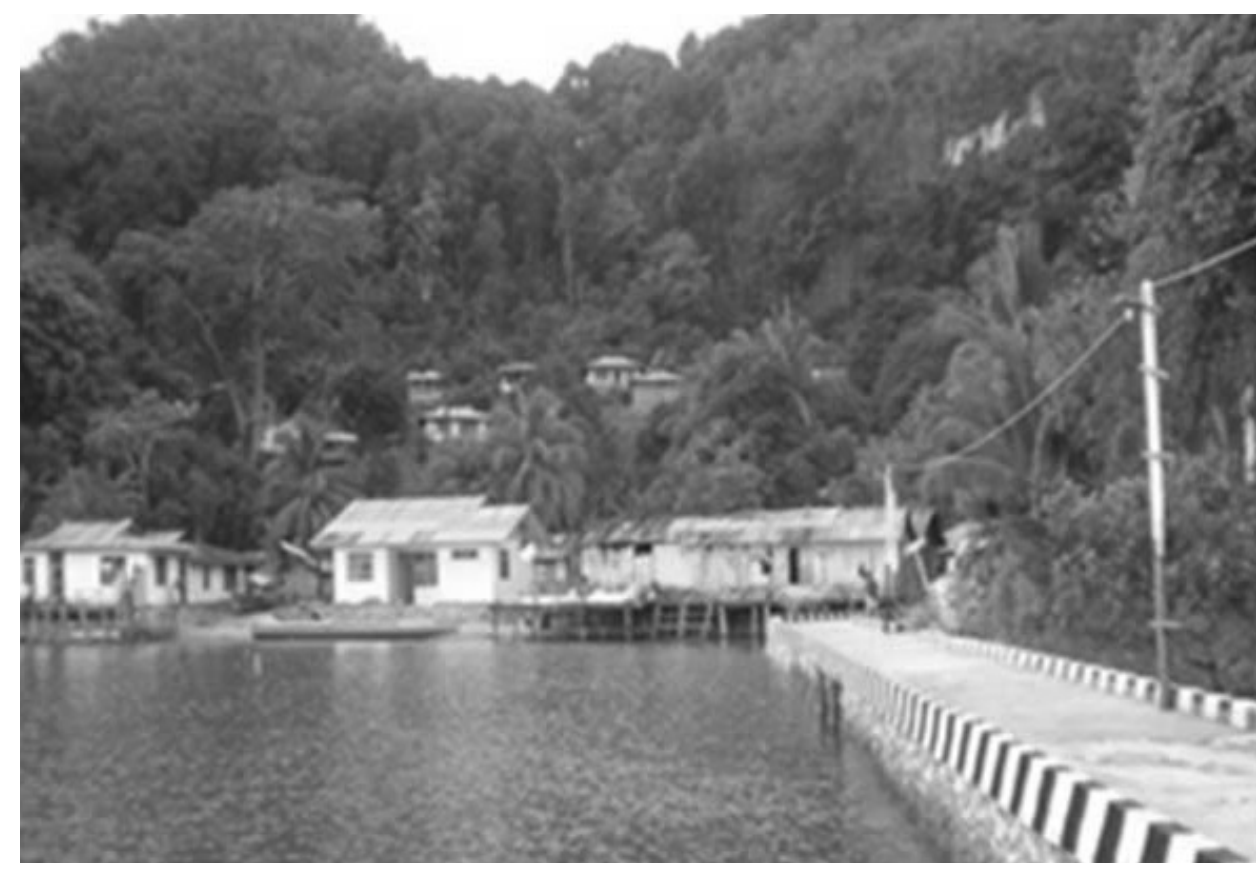

Gambar 1. Kampung Forir

(dokumentasi Balai Arkeologi Jayapura) 
waktu mereka melarikan diri itulah mereka melengkapi dirinya dengan "tomang"(tempat bekal makanan), "koba-koba" (senjata). Beberapa hari kemudian kapitan mengetahui kalau ayahnya sudah tewas dibunuh rekanrekannya yang juga melarikan diri ke daerah pesisir Pantai Kokas. Hati kapitan merasa sedih dan bercampur dendam untuk membalas kematian ayahnya.

Kapitan mulai menyusun rencana dengan mengajak rekan-rekannya untuk membentuk kekuatan baru. Setiap kali ia mengajak rekan-rekannya untuk berperang, namun selalu ditolak. Akhirnya kapitan marah, dan melarang rekan-rekannya untuk mencari makanan di sekitar pantai. Setiap kali menemukan rekan-rekannya sedang mencari makanan dan melukis di dinding tebing cadas, kapitan langsung menghapus lukisan-lukisan tersebut dan memukul mereka. Akhirnya rekanrekannya sekampung tidak menyukai dan tidak pernah lagi mengunjunginya ke gua tempat persembunyiannya.

Setelah sekian lama dia tidak pernah lagi dikunjungi oleh rekanrekannya, kapitan mulai sadar bahwa dirinya telah ditinggalkan oleh kelompoknya, dan merasa dirinya tidak berarti lagi, dan apalagi semua rencananya mengalami kegagalan. Suara merdu burungpun yang merdu terdengar tidak mampu juga menghibur dan menyembuhkan luka hatinya. Karena kapitan dalam waktu yang lama terus merenung dan mengurung diri di dalam gua dan karena putus asa akhirnya dia mengambil keputusan nekat dengan bunuh diri menggunakan "koba-koba"nya menyusul ayah saudara-saudaranya yang lain yang terlebih dahulu meninggalkan dunia/ tewas terbunuh dalam perang honggi. Tidak berapa lama kemudian rekanrekannya datang mengunjunginya, karena sudah lama mereka tidak melihatnya keluar gua. Betapa kagetnya mereka karena sesampainya di dalam gua, ternyata kapitan sudah matidan berubah bentuk meenjadibatu. demikian juga dengan senjata, serta tempat penyimpanan makanannya sudah berubah bentuk menjadi batu (Tim Peneliti 1996 : 3-5).

$$
\text { Cerita mitos merupakan }
$$
khasanah budaya yang tersirat, dan pesan moral yang dapat di petik diantaranya: perbuatan dendam yang membuat seseorang marah, dijauhi teman-temannya sehingga membuat dirinya frustasi akhirnya ia mengakhiri hidupnya dengan bunuh diri.

Cerita mitos dapat menjadi inspirasi yang menarik untuk dieksplor dan diekspos pada khalayak umum sebagai khasanah pengembangan ilmu budaya, yang merupakan perbendaharaan pemikiran warisan nenek moyang yang berguna juga untuk masa sekarang yang juga sebagai alat pendidik kepada masyarakat.

Pentingnya mengkaji nilai-nilai yang terkandung dalam cerita rakyat karena cerita rakyat itu memiliki fungsi kultural. Lahirnya suatu cerita rakyat bukan semata-mata di dorong oleh keinginan penutur untuk menghibur masyarakatnya melainkan dengan penuh kesabaran ia ingin menyampaikan nilai-nilai luhur kepada generasi penerusnya. Keberadaan cerita ini memiliki peran yang penting, salah satunya terkandung nilai sejarah, sosial, dan budaya. Nilai-nilai inilah yang memberikan gambaran dan pengalaman tersendiri pada masyarakat. Sebelum agama Islam masuk ke daerah ini, gua tersebut sering dijadikan sebagai tempat melakukan upacara keagamaan untuk meminta berkah kepada leluhur bahkan sampai saat ini pun tradisi ini masih dilakukan oleh masyarakat di Kampung Forir. 


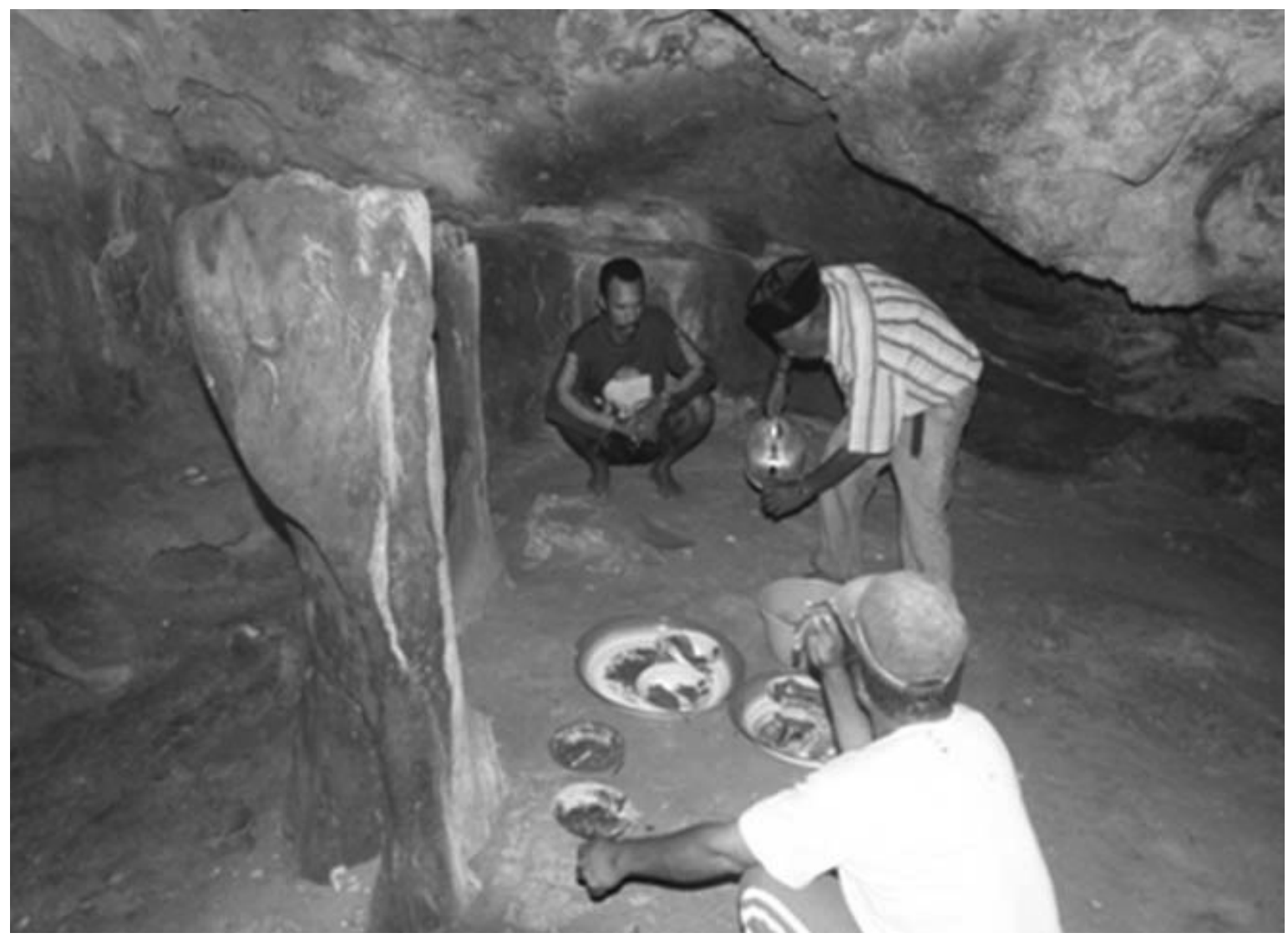

Gambar 2. Tradisi upacara sesajen di Gua Sosoraweru (dokumentasi Balai Arkeologi Jayapura)

\section{PENUTUP}

Tinggalan arkeologi di Gua Sosoraweru, di Kampung Forir, Distrik Kokas, Kabupaten Fakfak, berbentuk menhir dari bahan batu gamping (limestone), menhir tersebut berjumlah 4 buah. Tinggalan arkeologis tersebut dapat mengungkapkan cerita rakyat suku Baham. Tinggalan arkeologi tersebut sering dijadikan sebagai tempat melakukan upacara keagamaan untuk meminta berkah kepada leluhur bahkan sampai saat ini pun tradisi ini masih dilakukan oleh masyarakat
Kampung Forir, walaupun mereka sudah memeluk agama Islam. Tradisi tersebut menjadi wadah penguatan jati diri dan dipandang sebagai bagian penting dalam kehidupan, dan diyakini bahwa roh leluhur memiliki kekuatan sakti atau suci. Mereka menyakini bahwa media menhir dapat menghubungkan manusia dengan leluhurnya agar senantiasa memberi perlindungan kekuatan, dan dapat menolong dalam menghadapi kesulitan hidup. 


\section{DAFTAR PUSTAKA}

Abhasshare.blogspot.com (diakses tanggal 17 Juni 2014).

Endiraswara, Suwardi. 2013. Folklor Nusantara, Hakikat Bentuk, dan Fungsi. Yogyakarta: Ombak.

Galis, K.W. 1957. "Oude fortificatie ontdekta”. New Guinea Studien III.

Hoop, A.N.J. Th. Van der, 1932. Megalithik Remains in South Sumatra. Translated by W. Shirlaw, Zuthpen. W. J. Thieme \& Cie.

Lestari, Ria Fatimah Ummu. 2012. Mengungkapkan Cerita Rakyat Berdasarkan Temuan Purbakala di Pulau Ormu Kabupaten Jayapura. Jurnal Arkeologi Papua. Balai Arkeologi Jayapura.

Prasetyo, Bagyo. 2011. Budaya Pantai dan Pedalaman Masa Prasejarah di Papua dalam Austronesia dan Melanesia di Nusantara, mengungkapkan Asalusul dan Jati diri dari temuan Arkeologis. Yogyakarta: Penerbit Ombak kerjasama dengan Balai Arkeologi Jayapura.

Soejono, R.P. 1963. "Prehistori Irian Barat" dalam Penduduk Irian Barat. (Koentjaraningrat dan H.W.Bachtiar) Jakarta: Penerbit Universitas.

Soejono, R.P.1981. "Tinjauan Tentang Perangkaan Prasejarah Indonesia," dalam Aspek-aspek Arkeologi Indonesia No 5. Jakarta: Puslitarkenas.

Soejono, R.P.1984. "Jaman Prasejarah di Indonesia," dalam Sejarah Nasional Indonesia. Jakarta: Balai Pustaka.

Soejono, R.P.1977. Sistem-sistem Penguburan Pada Akhir Masa Prasejarah di Bali (Disertasi) Jakarta: Universitas Indonesia.

Tim Penelitian. 1996. Laporan Penelitian Arkeologi Bidang Arkeomentri di situs-situs Kokas, Kabupaten Fak-Fak Provinsi Irian Jaya. Balai Arkeologi Jayapura.

Tim Penelitian. 2012. Laporan Penelitian Arkeologi Eskavasi Situs Gua Sosoraweru Kampung Forir, Distrik Kokas Kabupaten Fakfak Provinsi Papua Barat. Balai Arkeologi Jayapura. 